\title{
Psychological Status and Irritable Bowel Syndrome among Healthcare Workers
}

\author{
By
}

\author{
Kasemy ZA ${ }^{1}$, Sakr AA ${ }^{2}$, EL Shebiny EM ${ }^{3}$, Elbasyouny $\mathbf{H A}^{3}$ \\ and EI Dalatony $\mathbf{M M}^{1}$ \\ ${ }^{I}$ Department of Public Health and Community Medicine, ${ }^{2}$ Department of Tropical \\ Medicine, ${ }^{3}$ Department of Internal Medicine, Faculty of Medicine, \\ Menoufia University, Egypt
}

Corresponding author: Kasemy ZA: zeinab.kasemy@med.menofia.edu.eg

\begin{abstract}
Introduction: Irritable bowel syndrome (IBS) is a functional gastrointestinal disorder with a global prevalence characterized by disturbances in bowel habits in the absence of known organic pathology. Psychological stress has been blamed to be a major factor leading to gastrointestinal symptoms. Aim of work: To assess the prevalence and predictors of irritable bowel syndrome (IBS) among healthcare workers (HCWs) together with assessment of the psychological status of this affected cohorts. Materials and methods: A retrospective cohort study was carried out during the period from November 2018 to June 2019 at a tertiary care hospitals in an Egyptian governorate on 622 participants distributed as HCWs $(\mathrm{No}=402)$ working at the studied hospitals and a control group $(\mathrm{No}=220)$ visiting the Family Medicine outpatient clinic at the same hospitals. A questionnaire including Rome III diagnostic criteria had been administered to the studied groups. Regarding the psychiatric state of the studied participants, the Arabic version of Taylor Manifest Anxiety Scale (TMA) and Beck Depression Inventory (BDI) scale were used. Results: The study showed that the prevalence of IBS was $14.4 \%$ among HCWs vs. $8.8 \%$ among controls. Regarding awareness of IBS, $73.4 \%$ of HCWs reported awareness vs. $23 \%$ among controls but regarding misconception of IBS, it was reported among $32.3 \%$ of controls vs. 17.7\% among HCWs. . Regarding psychiatric status, emotional stress, anxiety, depression, and mixed-status; the study reported higher percentage among IBS patients $\mathrm{P}<0.001$. Logistic regression was performed to ascertain the effects of sex, emotional stress, anxiety, depression, working hours and specialty on the likelihood that participants who have IBS and it was statistically significant, $\chi 2=75.15, \mathrm{p}<0.001$. The model correctly classified $87.6 \%$ of cases. HCWs suffering from emotional stress or depression were 2 and 3 times respectively more likely to exhibit IBS. Conclusion: IBS was more prevalent among HCWs together with psychiatric disorders giving high priority to in-depth analysis of the work environment to stand on all factors and finding a solution to this critical problem.
\end{abstract}

Keywords: Anxiety, Depression, Gastroenterology, Healthcare workers, Irritable bowel syndrome. 


\section{Introduction}

Irritable bowel syndrome (IBS) is a fairly common disorder that occurs in the general population. IBS is a functional bowel disorder associated with decreased work productivity, diminished quality of life, and increased healthcare costs (Tosun et al., 2016). IBS is a chronic biopsychological disorder that is "characterized by altered bowel habits with abdominal discomfort or pain with the absence of organic pathology". Besides the motility defect and distorted visceral perception of sensation, IBS is associated with several gastrointestinal and extra-intestinal manifestations (Qureshi et al., 2016). Patients with IBS suffer disturbances in their social and professional life and feel ashamed of their symptoms. They often change their eating habits and frequently resort to the healthcare services in a useless search for effective medical care (Mira et al., 2015). Several clinical studies and reports from different researchers have shown that, among patients seeking medical attention for IBS, 70-90\% may have psychiatric co-morbidity, most commonly mood disorders, anxiety disorders and somatization disorder (Tosic-Golubovic et al., 2010). The relationship between IBS and other functional bowel syndromes to psychiatric disorders remains uncertain. Psychiatric disturbance among persons with IBS might represent a reaction to the stress in the form of chronic gastrointestinal illness, but this possibility seems to have been excluded by the findings of lesser rates of psychiatric illness among patients with inflammatory bowel disorder (Kurina et al., 2001). IBS induces an occupational hazard as it affects the performance of patients at work. This was reported in a study from Canada where IBS became the second leading cause of absenteeism after the common cold. Chu et al., 2012 and Qureshi et al., 2016, conducted studies among medical, science, and engineering students in China, reported that medical students had a much higher risk of functional bowel disorders (FBD) than science and engineering students. In 2012 among medical students at the University of Western Ontario, Canada; they found that the prevalence of IBS among preclinical and clerkship students was $19.1 \%$ and $22.0 \%$, respectively (Ibrahim et al., 2013). According to our best of knowledge, no one studied IBS among healthcare workers in our region especially that they were suffering a lot in their job; so why this study was done. 


\section{Aim of work}

To assess the prevalence and predictors of IBS among Egyptian healthcare workers together with assessment of the psychological status of this affected cohorts.

\section{Materials and methods}

Study design: It is a retrospective cohort study

Place and duration of the study: This study was carried out at tertiary care hospitals in an Egyptian governorate during the period from November 2018 to June 2019.

Study sample: Based on the past review of literature showed that prevalence of IBS among healthcare professionals to be $13.5 \%$ (Tosun et al., 2016), the sample size had been calculated at CI 95\% and margin of error $3 \%$. It is estimated that 461 HCWs would be required. Twenty HCWs refused to share in the study while thirty nine were excluded from the study because of either having red flag symptoms $(\mathrm{No}=28)$ or systemic conditions affecting bowel movements like Type II diabetes mellitus $(\mathrm{No}=10)$ or multiple sclerosis $(\mathrm{No}=1)$. Finally the study was carried out on $402 \mathrm{HCWs}$ and 220 controls who were visiting the Family Medicine outpatient clinic of the same hospitals.
Inclusion criteria: All participants who agreed to share in the study were included.

Exclusion criteria: Individuals who refused to participate or were identified as having red flag symptoms, those with any systemic disorders (e.g., multiple sclerosis, diabetes mellitus, renal failure, systemic lupus erythematosus), those receiving antihypertensive drugs including calcium channel blockers and $\beta$-blockers), and patients with a thyroid function disorders.

Methods: The study was conducted on 402 HCWs and 220 controls. Within 3 months before carrying the study, routine laboratory investigations such as complete blood cell (CBC) count, fasting blood glucose, kidney function tests, thyroid hormones levels conducted were reviewed for both groups.

Both groups were subjected to a questionnaire containing inquiries about age, gender, specialty, years of experience, presence of any comorbidities, regular use of medication, smoking, awareness of IBS, presence of alarming red flag symptoms (drastic weight loss, organic bowel disease, digestive surgery, bloody stool, awakening night from abdominal pain, anemia, fever, or arthralgia). 
- Specific questions for the identification of IBS meeting ROME III diagnostic criteria: recurrent abdominal pain or discomfort at least 3 days a month in the past 3 months, associated with two or more of the following: Improvement with defecation, onset associated with a change in the frequency of stool and a change in the form of stool.

- Regarding the psychiatric state of the studied participants, the Arabic version of Taylor Manifest Anxiety Scale (TMA) and Beck Depression Inventory (BDI) scale were used (Taylor 1953 and Beck et al., 1961) .Definitions of psychiatric state assessment: (1) Normal: Patients with a TMA score $<16$ and BDI score < 10. (2) Depression: Patients with BDI scores $\geq 10$. (3) Anxiety: Patients with TMA scores $\geq 16$. (4) Mixed: Having both anxiety and depression criteria simultaneously.

\section{Consent}

A written informed consent was obtained from each participant after explaining the aim in full details with assurance of confidentiality and anonymity of data.

\section{Ethical Approval}

The study protocol was approved by the Ethical Committee of the department of Public Health and the Research Ethics Committee, Faculty of Medicine, Menofia University.

\section{Data management}

Results were statistically analyzed by SPSS version 22 (SPSS Inc., Chikago, IL, USA). Student's t-test was used for parametric data. MannWhitney was used for non-parametric data. Chi-Squared $\left(\chi^{2}\right)$ and Fisher's exact tests were used for qualitative variables. Regression analysis was used to detect the predictors of the disease. $p$ value $<0.05$ was considered significant. 


\section{Results}

\section{Table 1: Distribution of the studied groups according to their general} characteristics:

\begin{tabular}{|c|c|c|c|c|c|c|}
\hline & \multicolumn{2}{|c|}{ HCWs(No:402) } & \multicolumn{2}{|c|}{ Controls(No:220) } & \multirow[b]{2}{*}{$\chi^{2}$} & \multirow[b]{2}{*}{ p-value } \\
\hline & No & $\%$ & No & $\%$ & & \\
\hline Age (Mean \pm SD) & \multicolumn{2}{|c|}{$35.18 \pm 7.49$} & \multicolumn{2}{|c|}{$36.03 \pm 7.70$} & $\mathrm{t}=1.34$ & 0.181 \\
\hline \multicolumn{7}{|l|}{ Sex } \\
\hline Male & 146 & 36.3 & 70 & 31.8 & \multirow[t]{2}{*}{1.27} & \multirow[t]{2}{*}{0.260} \\
\hline Female & 256 & 63.7 & 150 & 68.2 & & \\
\hline \multicolumn{7}{|l|}{ Income } \\
\hline Sufficient & 254 & 63.2 & 166 & 75.5 & \multirow[t]{2}{*}{9.76} & \multirow[t]{2}{*}{$0.002 *$} \\
\hline Insufficient & 148 & 36.8 & 54 & 24.5 & & \\
\hline \multicolumn{7}{|l|}{ Residence } \\
\hline Urban & 194 & 48.3 & 113 & 51.4 & \multirow[t]{2}{*}{0.54} & \multirow[t]{2}{*}{0.459} \\
\hline Rural & 208 & 51.7 & 107 & 48.6 & & \\
\hline \multicolumn{7}{|l|}{ Smoking } \\
\hline Yes & 44 & 11.4 & 10 & 4.5 & \multirow[t]{2}{*}{8.25} & \multirow[t]{2}{*}{$0.004 *$} \\
\hline NO & 358 & 88.6 & 210 & 95.5 & & \\
\hline \multicolumn{7}{|l|}{ BMI } \\
\hline Normal & 106 & 26.4 & 55 & 25.0 & \multirow[t]{3}{*}{0.39} & \multirow[t]{3}{*}{0.821} \\
\hline Overweight & 174 & 43.3 & 93 & 42.3 & & \\
\hline Obese & 122 & 30.0 & 72 & 32.7 & & \\
\hline \multicolumn{7}{|l|}{ Physical activity } \\
\hline Yes & 46 & 11.4 & 20 & 9.1 & \multirow[t]{2}{*}{0.82} & \multirow[t]{2}{*}{0.363} \\
\hline NO & 356 & 80.6 & 200 & 90.9 & & \\
\hline \multicolumn{7}{|l|}{ Regular use of medications } \\
\hline Yes & 118 & 29.4 & 20 & 9.1 & \multirow[t]{2}{*}{33.81} & \multirow[t]{2}{*}{$<0.001 * *$} \\
\hline NO & 284 & 70.6 & 200 & 90.9 & & \\
\hline \multicolumn{7}{|l|}{ Comorbidities } \\
\hline Yes & 26 & 6.5 & 13 & 5.9 & \multirow[t]{2}{*}{0.07} & \multirow[t]{2}{*}{0.784} \\
\hline $\mathrm{NO}$ & 376 & 93.5 & 207 & 94.1 & & \\
\hline \multicolumn{7}{|c|}{$\begin{array}{l}\text { *: Statistically significant } \\
\text { Table } 1 \text { showed that there was no statistically significant difference between the } \\
\text { studied groups as regards age or sex }(\mathrm{p}=0.181 \text { and } 0.260 \text { respectively). Sufficient } \\
\text { income was statistically significantly higher among controls }(75.5 \%) \text { than HCWs } \\
(63.2 \%)(\mathrm{p}=0.002) \text {. Smoking and regular use of medication, were statistically } \\
\text { significantly higher among HCWs }(11.4 \% \text { and } 29.4 \% \text { respectively) compared to } \\
\text { controls }(4.5 \% \text { and } 9.1 \% \text { respectively) }(\mathrm{p}=0.004 \text { and }<0.001 \text { respectively). }\end{array}$} \\
\hline
\end{tabular}




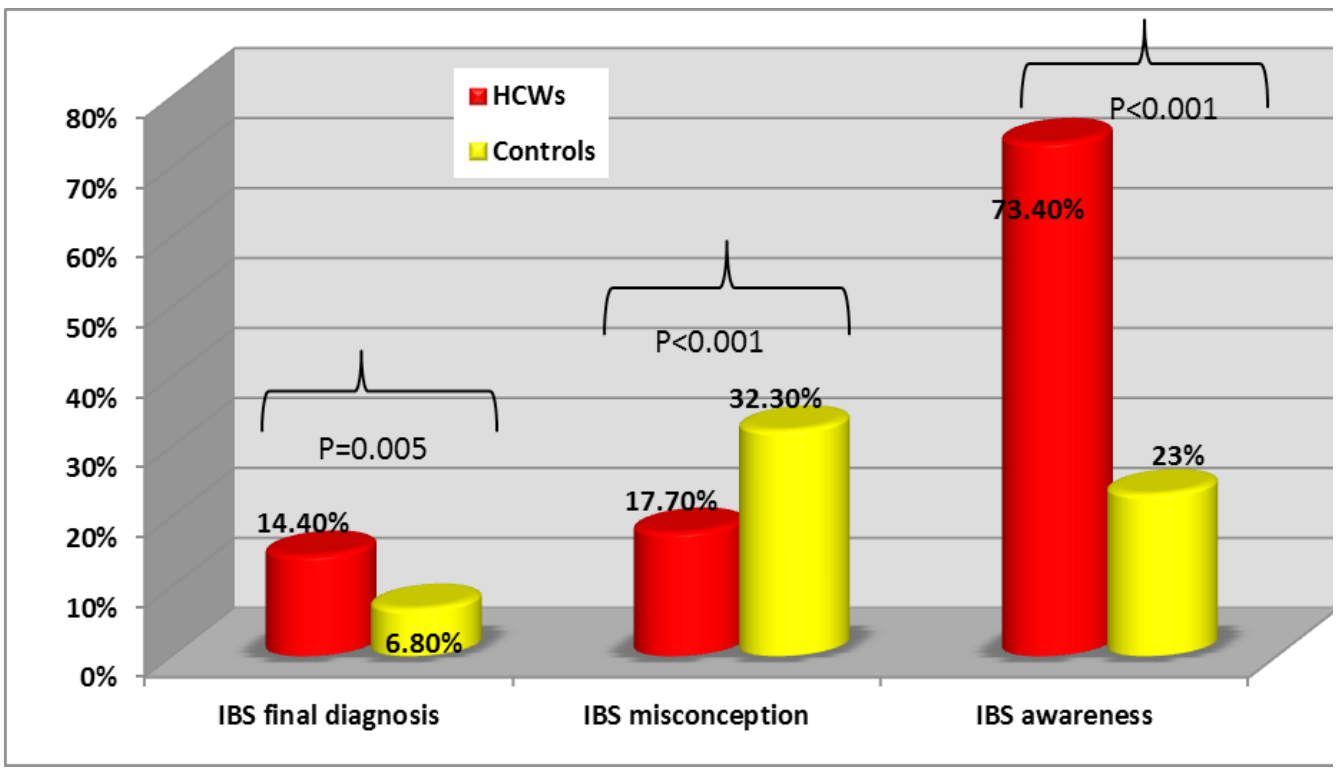

Fig 1: Distribution of the studied groups regarding final diagnosis, misconception and awareness of irritable bowel syndrome.

Fig 1 showed that the prevalence of IBS was $14.4 \%$ among HCWs versus $6.8 \%$ among controls. Regarding awareness of IBS, $73.4 \%$ of HCW reported awareness versus $23 \%$ among controls but regarding misconception of IBS, it was reported among $32.3 \%$ of controls vs. $17.7 \%$ among HCWs. 
Table 2: Distribution of the studied physicians and nurses regarding their general characteristics:

\begin{tabular}{|c|c|c|c|c|c|c|}
\hline & \multicolumn{2}{|c|}{ Physicians(No:238) } & \multicolumn{2}{|c|}{ Nurses(No:164) } & \multirow[b]{2}{*}{$\chi^{2}$} & \multirow[b]{2}{*}{ p-value } \\
\hline & No & $\%$ & No & $\%$ & & \\
\hline$\overline{\text { Age }}$ & \multicolumn{2}{|c|}{$33.34 \pm 6.81$} & \multicolumn{2}{|c|}{$37.84 \pm 7.65$} & 6.19 & $<0.001 * *$ \\
\hline Years of experience & \multicolumn{2}{|c|}{$6.89 \pm 5.05$} & \multicolumn{2}{|c|}{$13.52 \pm 6.66$} & 9.14 & $<0.001 * *$ \\
\hline \multicolumn{7}{|l|}{ Sex } \\
\hline Male & 108 & 45.4 & 38 & 23.2 & 20.70 & $<0.001 * *$ \\
\hline Female & 130 & 54.6 & 126 & 76.8 & & \\
\hline Smoking & 41 & 17.2 & 19 & 11.7 & 2.30 & 0.129 \\
\hline \multicolumn{7}{|l|}{ BMI } \\
\hline Normal & 83 & 35.0 & 23 & 13.9 & & \\
\hline Overweight & 110 & 46.4 & 64 & 38.8 & 44.11 & $<0.001 * *$ \\
\hline Obese & 44 & 18.6 & 78 & 47.3 & & \\
\hline Comorbidities & 18 & 7.6 & 8 & 4.8 & 1.21 & 0.271 \\
\hline Regular use of drugs & 64 & 27.0 & 54 & 32.7 & 1.53 & 0.215 \\
\hline IBS misconception & 27 & 11.4 & 44 & 26.7 & 15.60 & $<0.001 * *$ \\
\hline IBS awareness & 229 & 96.6 & 66 & 40.0 & 159.68 & $<0.001 * *$ \\
\hline IBS final diagnosis & 42 & 17.7 & 16 & 9.7 & 2.07 & $0.024 *$ \\
\hline
\end{tabular}

*: Statistically significant

**: Highly statistically significant

BMI: Body Mass Index

IBS: Irritable Bowel Syndrome

Table 2 showed that there were statistically significant differences between the studied physicians and nurses groups regarding age $(33.34 \pm 6.81$ vs. 37.84 $\pm 7.65),(\mathrm{p}<0.001)$ and years of experience $(6.89 \pm 5.05$ vs.13.52 \pm 6.66$),(\mathrm{p}<0.001)$. Regarding sex, female sex was significantly higher among nurses $(76.8 \%)$ than among physician $(54.8 \%)(\mathrm{p}<0.001)$. IBS awareness, was statistically significantly higher among physicians (96.6\%) than among nurses (40\%), but interestingly nurses showed higher misconception of IBS $(26.7 \%)$ than physicians $(11.4 \%),(p<0.001)$. IBS was statistically significantly higher among physicians when compared to nurses. 
Table 3: Distribution of irritable bowel syndrome (IBS) among healthcare workers regarding associated risk factors:

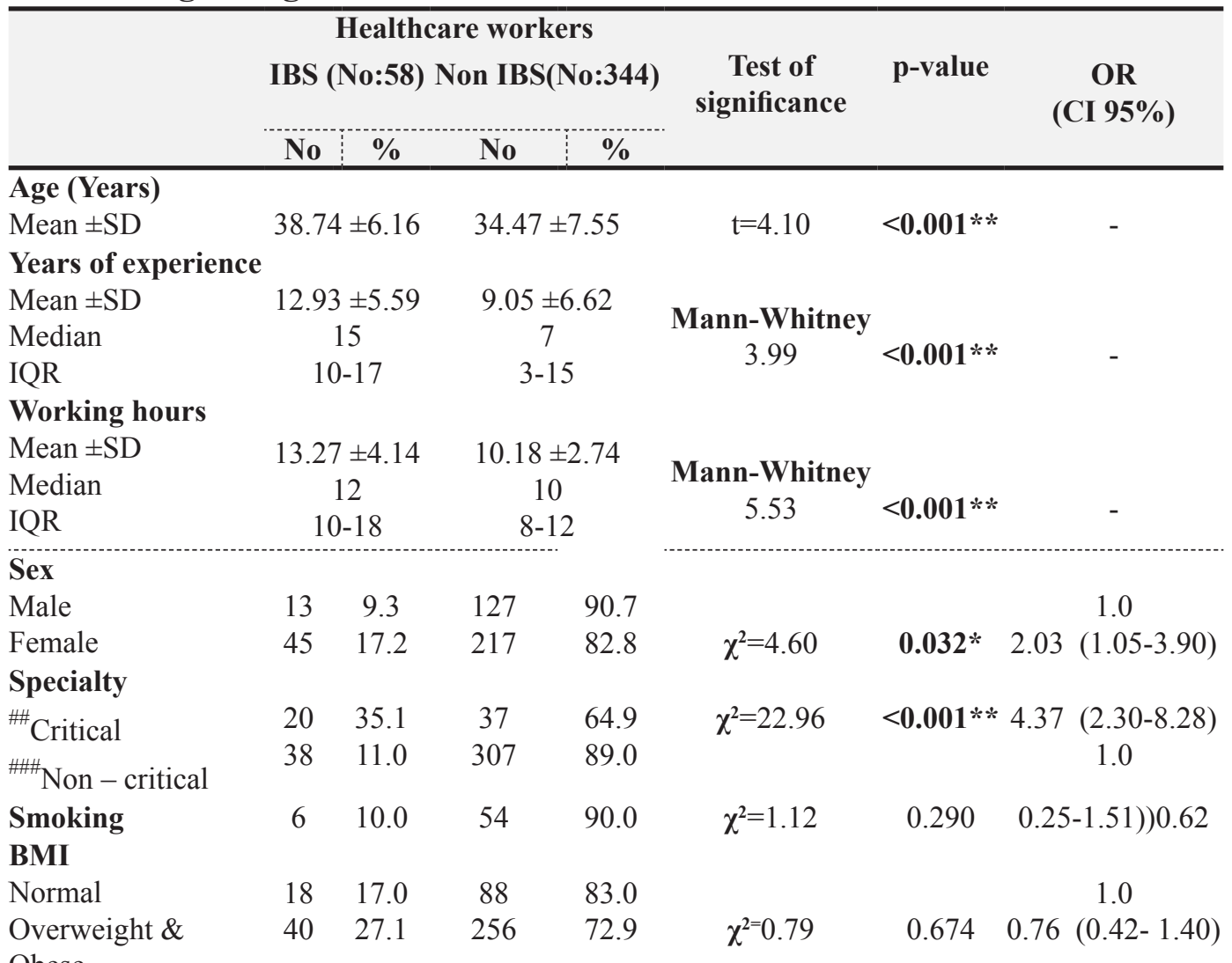

Obese

Physical activity

Yes

$\begin{array}{llll}2 & 3.4 & 44 & 95.7\end{array}$

1.0

NO

$\begin{array}{llll}56 & 15.7 & 300 & 84.3\end{array}$

$\chi^{2}=4.27$

$\mathbf{0 . 0 3 9 * \quad 0 . 0 6 - 1 . 0 3 ) ) 0 . 2 4}$

Psychometric tests \#

\begin{tabular}{lccccccc} 
Emotional stress(+ve) & 33 & 56.9 & 119 & 34.6 & 10.50 & $\mathbf{0 . 0 0 1} *$ & $1.33-4.46)) 2.44$ \\
Anxiety (+ve) & 41 & 70.7 & 171 & 49.7 & 8.76 & $\mathbf{0 . 0 0 3} *$ & $1.70-5.70)) 3.11$ \\
Depression(+ve) & 41 & 70.7 & 150 & 43.6 & 14.60 & $<\mathbf{0 . 0 0 1} * *$ & $1.41-4.39)) 2.49$ \\
Mixed (+ve) & 29 & 50.0 & 91 & 26.5 & 13.14 & $<\mathbf{0 . 0 0 1 * *} 2.78(1.57-4.90)$ \\
\hline
\end{tabular}

\#: Statistically significant

\#\#: Highly statistically significant

\#: \% from column

BMI: Body Mass Index

IQR: Interquartile Range

${ }^{\# \#}$ Critical: All surgical specialties and Intensive care units ICUs)

\#\#\# Non -critical: Internal Medicine, Tropical, Radiology departments etc... 
Table 3 showed that IBS patients had higher age (37.74 \pm 6.16$)$, excess years of experience (37.74 \pm 6.16$)$ and working hours (13.24 \pm 4.18$)$ in comparison with nonIBS $(p<0.001)$. Also IBS was higher among HCWs working in critical specialties in comparison with non-critical ones $(\mathrm{p}<0.001)$. Interestingly the results showed that $3.4 \%$ of IBS performed physical activity in comparison to $12.8 \%$ among non-IBS. Regarding psychometric tests, the results showed that IBS HCWs had statistically significantly poorer status in comparison with non IBS ones where emotional stress was reported among $56.9 \%$ vs. $34.6 \%$, depression among $70.7 \%$ vs. 43.6 , anxiety among $70.7 \%$ vs. $49.7 \%$, and mixed-status (depression and anxiety) among 50\% vs. $26.5 \%$.

Table 4: Binary logistic regression for predictors of the irritable bowel syndrome among healthcare workers:

\begin{tabular}{|l|c|c|c|c|c|}
\hline \multirow{2}{*}{\multicolumn{1}{c|}{ Variables }} & & \multirow{2}{*}{ Wald } & \multirow{2}{*}{ p-value } & \multirow{2}{*}{ OR } & \multicolumn{2}{c|}{ 95\% CI } \\
\cline { 5 - 7 } & & Lower & Upper \\
\hline Sex (Females) & 7.92 & $* \mathbf{0 . 0 0 5}$ & 0.31 & 0.13 & 0.70 \\
\hline Emotional stress(Yes) & 4.11 & $\mathbf{0 . 0 4 2 *}$ & 2.06 & 1.02 & 4.16 \\
\hline Anxiety(Yes) & 0.83 & 0.361 & 1.43 & 0.66 & 3.11 \\
\hline Depression (Yes) & 10.90 & $\mathbf{0 . 0 0 1 * *}$ & 3.62 & 1.68 & 7.79 \\
\hline Working hours & 22.42 & $<\mathbf{0 . 0 0 1 * *}$ & 1.68 & 0.82 & 3.45 \\
\hline Specialty (Critical) & 2.05 & 0.152 & 0.80 & 0.73 & 0.87 \\
\hline Physical activity (NO) & 1.06 & 0.302 & 2.20 & 0.49 & 9.93 \\
\hline Constant & 1.27 & 0.259 & 5.08 & & \\
\hline
\end{tabular}

*: Statistically significant

**: Highly statistically significant

Table 4 showed the results of logistic regression performed to ascertain the effects of sex, emotional stress, anxiety, depression, working hours and specialty on the likelihood that participants have IBS. The logistic regression model was statistically significant, $\chi 2=75.15, \mathrm{p}<0.001$. The model correctly classified $87.6 \%$ $\%$ of cases. HCWs suffering from emotional stress or depression were 2 and 3 times respectively more likely to exhibit IBS. 


\section{Discussion}

Irritable bowel syndrome is a chronic disorder that affects every day's contexts and gives rise to high social and health service costs and emotional problems among sufferers (TosicGolubovic et al., 2010). To the best of our knowledge, this is the first study done to identify the prevalence, severity, and predictors of IBS among HCWs at tertiary care hospitals in an Egyptian governorate. Accurate measurement of IBS prevalence is quite difficult as it depends on different factors, including age, sex, etc. Regardless of the aforementioned factors, the study showed that the prevalence of IBS was $14.4 \%$ among $\mathrm{HCWs}$ versus $6.8 \%$ among controls with a total prevalence of $11.7 \%$ (Fig 1). This is in agreement with Tosun et al., 2016 who reported that the frequency of IBS was $13.5 \%$ among physicians and nurses and $6.1 \%$ among the control group. According to Qureshi et al., 2016, the prevalence of IBS in the general population of Western countries ranges from $15 \%$ $24 \%$. While in Asia the prevalence was around $5-10 \%$, which is similar to our results and lower compared to Western societies. The high prevalence among HCWS in comparison to controls in the current study agrees with the studies of
( Ho et al., 2009, Mealer et al., 2009, Kemper et al., 2011 Gregov et al., 2014, Tosun et al., 2016 and Shackelton et al 2019) which proved that medicine and nursing are occupations associated with a high level of stress as healthcare personnel are exposed to intensive stress in their daily lives because of the nature of their occupation and work environment, in which they are often competing against time.

The results of the present study revealed a higher level of IBS awareness among HCWs compared to control group (Fig 1) This was in accordance with the study of done by Tosun et al., 2016 on frequency of IBS among healthcare personnel gastroenterology nursing detected that physicians had significantly greater knowledge about IBS.

The current study showed a significant difference among physicians and nurses within the healthcare group concerning mean age, years of experience and sex (Table 2). These findings coincide with the study of Elsaieda et al., 2017 on socio-demographic factors and anxiety: depressive disorders among irritable bowel syndrome patients; and reported that IBS was higher among women compared to men in Western countries, the female: male odds ratio 
was $2: 1$, and seems to be more common in individuals between 20 and 40 years of age. Based on the different symptoms observed, the researchers speculated that sex hormones may alter the regulatory mechanisms of the braingut-microbiota axis involved in the pathophysiology of IBS .These results reflect that nurses are more likely to have stress-related disorders such as gastro-esophageal reflux disease (GERD), gastritis, and hypertension which may be due to earlier starting age in this stressful working conditions and/or nurses are in direct contact with patients most of the time so they are more exposed to more stressful situations. Psychosocial factors were known to affect the development of IBS (Surdea-Blaga et al., 2012).

The current work revealed that the prevalence of IBS among nurses was $9.7 \%$ (Table 2) which was lower than the results detected by Ibrahim et al., 2016 in their study on the prevalence and predictors of irritable bowel syndrome among medical students and interns in King Abdulaziz University, Jeddah, who detected that the prevalence was $14.4 \%$, which is near to the prevalence among physician (Table 2) and this may be due to that more stress is experienced by physicians in Egypt.
Due to the nature of their occupation, HCWs are exposed to severe stress in their daily lives and the stressful work environment, in which time is the main competitor; they are often falling as victims to psychological disorders. When we compare between IBS and non-IBS HCWs concerning the results of the Psychometric tests; it revealed a higher prevalence of emotional stress, anxiety, depression, and mixed symptoms among those HCWs who were diagnosed as having IBS compared to the non-IBS HCWs using Rom III criteria (Table 2). These results were similar-with that of Zaghloul et al., 2009, Kemper et al., 2011, and Shackelton et al 2019 who stated that stress and stressful lifestyle led to the development of IBS. Also Drews et al., 2008 declared that individuals who worry excessively and suffer from Generalized Anxiety Disorder (GAD) may especially be prone to such gastrointestinal distress, one of the many somatic symptoms historically associated with this anxiety disorder. Other American studies reported that anxiety disorders were highly prevalent in IBS outpatients (39.7-52.4\%) (Blanchard et al., 2001). Tan et al., 2003 found that symptoms of anxiety and depression were more commonly 
encountered among Malaysian medical students with IBS than others. Similarly, Okami et al., 2011 detected that medical students with IBS had significantly higher stress scores (anxiety and depression) and stressful life events than the non-IBS group. In addition to the finding of Ibrahim et al., 2013 who stated in his study that $40.1 \%$ of medical students in Jeddah who faced emotional stress suffered from IBS compared with $20.1 \%$ among those without such stress and that morbid anxiety is a predictor of IBS in Jeddah. Also Naeem et al., 2012 found that the psychological symptoms of anxiety were significantly higher among IBS students than among those who did not suffer from IBS.

The distribution of the studied IBS and Non-IBS among HCW regarding their associated factors, a comparison that highlighted a significant difference between both IBS and Non-IBS regarding age, work experience, daily working hours, working in critical specialties, and their level of physical activity (Table 3). Basandra et al., 2014 detected that IBS was significantly associated with inadequate practicing of physical activities among Indian medical students. Costanian et al., 2015 declared that students who were practicing regular physical exercises had a significantly lower prevalence of IBS. This was also, stated by other studies which reported the protective effect of physical activity (Dong et al., 2010 and Ibrahim et al., 2013).

In the current study; female gender presents a significant factor in the occurrence of IBS (Table 3). This was in agreement with Okami et al., 2011 who reported that females had a higher risk of IBS than males. Also, the study of Liu et al., 2014 showed that women were nearly two-timed more likely to report symptoms of IBS than men and the study of Ibrahim et al., 2013 ; who reported that the first predictor of IBS was the female gender. This can be explained by the fact that females are facing more risk of exposure to stress at work and at home.

Logistic regression was performed to ascertain the effects of sex, emotional stress, anxiety, depression, working hours and specialty on the likelihood that participants have IBS (Table 4). HCWs with emotional stress and depression were 2 and 3 times respectively more likely to exhibit IBS. This was in agreement with the study of (Lee et al., 2015) who reported that stress and depression were among the risk factors of IBS and the rates of IBS increased along with increasing stress levels. 
Belgium study of Wouters et al., 2015 reported an increased risk of patients with psychological co-morbidity to develop post-infectious IBS. A Turkish case-control study stated that depression among IBS cases was significantly much higher (38\%) than among the controls (4\%) (Uz et al., 2007). Another study revealed high rates of psychiatric disorders among IBS patients have been reported: $46 \%$ for depression, $34 \%$ generalized anxiety disorder , 31\% panic disorder and $26 \%$ somatization disorder (Tosic-Golubovic et al., 2010).

\section{Conclusion}

Irritable bowel syndrome is a gastrointestinal problem found to be highly related to certain risk factors. Those risk factors include but not limited to sex, age, psychological conditions highly predominant in our modern life as anxiety and depression. Healthcare providers are exposed routinely during their daily work to highly stressful conditions so they are one of the most common categories at risk of developing IBS especially nurses who are in continuous contact with patients during their duty. Based on the abovementioned causes we recommend more and more investigations of the work environment conditions in the healthcare facilities to lower the psychological burden on healthcare providers.

\section{Conflict of interest}

All authors declare that there is no conflict of interest. The manuscript represents valid work; neither this manuscript nor one with substantially similar content under our authorship has been published or is being considered for publication elsewhere.

\section{Funding}

None

\section{Acknowledgment}

Special thanks to all HCW and controls who agreed to give us some of their precious time. Also great thanks to Abdel Fattah Shahin, a $5^{\text {th }}$ grade student at faculty of Medicine in Menoufia University, who helped us to collect the data.

\section{References}

1. Basandra S and Bajaj D (2014): Epidemiology of Dyspepsia and Irritable Bowel Syndrome (IBS) in Medical Students of Northern India. J Clin Diagn Res; 8: JC13-6. doi: 10.7860/ JCDR/2014/10710.5318.

2. Beck AT, Ward CH, Mendelson M, Mock J and Erbaugh J (1961): An inventory for measuring depression. Arch Gen Psychiatry; 4:561-71. doi:10.1001/ archpsyc.1961.01710120031004. 
3. Blanchard EB, Keefer L, Galovski TE, Taylor AE and Turner SM (2001): Gender differences in psychological distress among patients with irritable bowel syndrome. J Psychosom Res; 50:271-5. doi :10.1016/ s0022-3999(01)00207-0.

4. Chu L, Zhou H, Lu“ B, Li M and Chen MY (2012): An epidemiological study of functional bowel disorders in Zhejiang college students and its relationship with psychological factors. Zhonghua Nei Ke Za Zhi; 51(6):429-32. PMID: 22943750.

5. Costanian $\mathrm{C}$, Tamim $\mathrm{H}$ and Assaad $\mathrm{S}$ (2015): Prevalence and factors associated with irritable bowel syndrome among university students in Lebanon: Findings from a cross-sectional study. World $\mathrm{J}$ Gastroentero; 21: 3628-35. doi: 10.3748/ wjg.v21.i12.3628.

6. Dong YY, Zuo XL, Li CQ, Yu YB, Zhao QJ, et al. (2010): Prevalence of irritable bowel syndrome in Chinese college and university students assessed using Rome III criteria. World J Gastroentero; 16: 42216. doi:10.3748/wjg.v16.i33.4221.

7. Drews A and Hazlett-Stevens H (2008): Relationships between irritable bowel syndrome, generalized anxiety disorder, and worry-related constructs. Int J Clin Health Psychol; 8(2):429-36.
8. Elsaieda HF, Sherraa KS, Mahmouda EM and Ebrahim MA (2017): A study of sociodemographic factors and anxiety: depressive disorders among irritable bowel syndrome patients. Egypt J Psychiatr; 38:97-104 doi: 10.4103/11101105.209680

9. Gregov L, Kovac `evic'A and Sliškovic'A (2011): Stress among Croatian physicians: Comparison between physicians working in emergency medical service and health centers-Pilot study. Croat Med J; 52: 8 15. doi: 10.3325/cmj.2011.52.8.

10. Ho WH, Chang CS, Shih YL and Liang RD (2009): Effects of job rotation and role stress among nurses on job satisfaction and organizational commitment. BMC Health Serv Res; 9: 8. doi.org/10.1186/14726963-9-8

11. Ibrahim NK, Battarjee WF and Almehmadi SA (2013): Prevalence and predictors of irritable bowel syndrome among medical students and interns in King Abdulaziz University, Jeddah. Libyan J Med; 8:1-9. Available at: https://doi.org/10.3402/ljm. v8i0.21287.

12. Ibrahim NK, Al-Bloushy RI, Sait SH, AlAzhary HW, Al Bar NH, et al.,(2016): Irritable bowel syndrome among nurses working in King Abdulaziz University Hospital, Jeddah, Saudi Arabia. Libyan J Med; 30: 11:30866. doi: 10.3402/ljm. v11.30866. 
13. Kemper K, Bulla S, Krueger D, Ott M J, McCool JA, et al., (2011): Nurses experiences, expectations, and preferences for mind-body practices to reduce stress. BMC Complement Altern Med; 11:26. doi: 10.1186/1472-6882-11-26.

14. Kurina LM, Goldacre MJ, Yeates D and Gill LE (2001): Depression and anxiety in people with inflammatory bowel disease. J Epidemiol Commun H; 55:71620. doi:10.1136/jech.55.10.716.

15. Lee SP, Sung IK, Kim JH, Lee SY, Park HS, et al., (2015): The effect of emotional stress and depression on the prevalence of digestive diseases. J Neurogastroenterol Motil ; 21: 273-82. doi:10.5056/jnm14116.

16. Liu Y, Liu L, Yang Y,Yuxi He, Zhang Y, et al., (2014): A School-Based Study of Irritable Bowel Syndrome in Medical Students in Beijing, China: Prevalence and Some Related Factors. Gastroenterol Res Pract; 124261: 1-8. Available at: https:// doi.org/10.1155/2014/124261.

17. Mealer M, Burnham EL, Goode CJ, Rothbaum B and Moss M (2009): The prevalence and impact of post-traumatic stress disorder and burnout syndrome in nurses. Depress Anxiety; 26: 1118-26. Available at: http://dx.doi.org/10.3402/ljm. v8i0.21287.

18. Mira JJ, Guilabert M, Sempere L, Almenta IM, Palazón JM, et al., (2015): The irritable bowel syndrome care process from the patients' and professionals' views. Rev Esp Enferm Dig Madrid; 107(4): 202-10.
19. Naeem SS, Siddiqui EU, Kazi AN, Memon AA, Khan ST, et al., (2012): Prevalence and factors associated with irritable bowel syndrome among medical students of Karachi, Pakistan: a cross-sectional study. BMC Res Notes; 5: 255. doi: 10.1186/17560500-5-255.

20. Okami Y, Kato T, Nin G, Harada K, Aoi W, et al. (2011): Lifestyle and psychological factors related to irritable bowel syndrome in nursing and medical school students. J Gastroenterol; 46: 1403. doi:10.1007/s00535-011-0454-2.

21. Qureshi SR, Abdelaal AM, Janjua ZA, Alasmari HA, Obad AS, et al. (2016). Irritable Bowel Syndrome: A Global Challenge Among Medical Students Cureus; 8(8): 721. doi: 10.7759/cureus. 721.

22. Shackelton R, Siegrist J, Link C, Marceau L, von dem Knesebeck O, et al., (2010): Work stress of primary care physicians in the US, UK and German health care systems. Soc Sci Med; 71:298-304. doi: 10.1016/j.socscimed.2010.03.043.

23. Surdea-Blaga T, Băban A, and Dumitrascu DL. (2012): Psychosocial determinants of irritable bowel syndrome. World $\mathrm{J}$ Gastroenterol; 18(7): 616-26. doi: 10.3748/ wjg.v18.i7.616.

24. Tan YM, Goh KL, Muhidayah R, Ooi CL and Salem O (2003): Prevalence of irritable bowel syndrome in young adult Malaysians: a survey among medical students. J Gastroen Hepatol; 18:1412-6. doi:10.1046/j.1440-1746.2003.03212.x. 
25. Taylor J (1953): A personality scale of manifest anxiety. J Abnorm Soc Psychol; 48:285-90. doi:10.1037/h0056264.

26. Tosic-Golubovic S, Miljkovic S , Nagorni A, Lazarevic D and Nikolic G (2010): Irritable Bowel Syndrome, Anxiety, Depression And Personality Characteristics. Psychiatr Danub; 22 (3): 418-24. Available at: https://hrcak.srce.hr/ file/113438.

27. Tosun O, Dabak R, Sargin M, Dolapcioglu C and Ahishali E (2016): Frequency of Irritable Bowel Syndrome among Healthcare Personnel. Gastroenterol Nurs; 39(3):227-31. Available at https://www. researchgate.net/publication/303777170
28. Uz E, Turkay C, Aytac S and Bavbek N (2007): Risk factors for irritable bowel syndrome in Turkish population: role of food allergy. J Clin Gastroenterol; 41: 380-3. doi:10.1097/01. mcg.0000225589.70706.24

29. Wouters MM, Wanrooy SV, Nguyen A, Dooley J, Lizarraga JA, et al. (2015): Psychological comorbidity increases the risk for postinfectious IBS partly by enhanced susceptibility to develop infectious gastroenteritis. Neurogastroent; 65:127988. doi: 10.1053/j.gastro.2015.12.034.

30. Zaghloul AA and Abou El Enein NY (2009): Nurse stress at two different organizational settings in Alexandria. J Multidiscipl Hlth care; 2: 45-51. PMID: 21197346 